\title{
O POVO KAMBA NA FRONTEIRA ENTRE BRASIL E BOLÍVIA': UM ESTUDO JURÍDICO SOBRE VIOLAÇÃO DE DIREITOS HUMANOS
}

Antônio Hilário Aguilera Urquiza

Mestre em Educação (Educação Indígena) pela Universidade Federal de Mato Grosso (1999); Master em Educação (Tecnologias de la educación - 2001) e Doutorado em Antropologia pela Universidade de Salamanca - Espanha (2006). Professor associado da UFMS. Professor da graduação, especialização e do mestrado em direito da UFMS. Bolsista produtividade PQ2 do CNPq - Conselho Nacional de Desenvolvimento Científico e Tecnológico. Pesquisador e orientador no projeto de pesquisa "Análise do tráfico e migração de pessoas na fronteira de Mato Grosso do Sul: dinâmicas se modalidades". Coordenador do projeto de pesquisa: Fronteiras étnicas e culturais - Análise do tráfico e migração de pessoas na fronteira de Mato Grosso do Sul.

\section{LuCiani Coimbra de Carvalho}

Mestre em Doutora em Direito do Estado pela PUC/SP. Professora adjunta da UFMS. Professora da graduação, especialização e do mestrado em direito da UFMS. Coordenadora do projeto de pesquisa "Análise do tráfico e migração de pessoas na fronteira de Mato Grosso do Sul: dinâmicas se modalidades". Pesquisadora no projeto de pesquisa "Fronteiras étnicas e culturais - Análise do tráfico e migração de pessoas na fronteira de Mato Grosso do Sul".

\section{Resumo}

Este artigo apresenta resultados parciais do projeto de pesquisa interdisciplinar e interinstitucional desenvolvido por nós e que aborda a situaçáo jurídica do povo Kamba, índios bolivianos que cruzaram a fronteira Bolívia/Brasil, há mais de cinquenta anos e se estabeleceram na área urbana da cidade brasileira fronteiriça sul-mato-grossense de Corumbá, em um lugar que era o antigo lixão. $\mathrm{O}$ artigo contrasta o compromisso internacional assumido pela República Federativa do Brasil em garantir os direitos humanos dos

1 Artigo com resultados parciais da pesquisa desenvolvida no projeto interinstitucional "Análise do tráfico e migraçáo de pessoas na fronteira de Mato Grosso do Sul: dinâmicas se modalidades" com fomento da FUNDECT - Fundação de Apoio ao Desenvolvimento do Ensino, Ciência e Tecnologia do Estado de Mato Grosso do Sul e resultados parciais da pesquisa "Fronteiras étnicas e culturais - Análise do tráfico e migraçáo de pessoas na fronteira de Mato Grosso do Sul”, com fomento do CNPq. 
migrantes e indígenas localizados no país, com a realidade do povo Kamba que, até o presente momento, não foi reconhecido como indígena pela FUNAI - Fundação Nacional do Índio e, portanto, encontra-se à margem do exercício de direitos humanos garantidos aos indígenas e sem usufruir de direitos e políticas públicas específicas. Revela também a situação de migrante em uma sociedade discriminatória e sem políticas públicas efetivas de acolhimento e igualdade material de direitos humanos entre nacionais e estrangeiros, que vive em situação de vulnerabilidade social, vítima de discriminação e de exploraçáo do trabalho. A pesquisa é de natureza exploratória tendo sido utilizados dados primários e secundários coletados na doutrina, legislação e pesquisa de campo.

\section{Palavras-chave}

Direitos Humanos; Fronteira; Indígenas e Migração.

\section{Resumen}

Este artículo presenta resultados parciales de proyecto de investigación interdisciplinar e interinstitucional desarrollado por nosotros y que trata de la situación jurídica del pueblo Kamba, indios bolivianos que cruzaran la frontera Bolivia/Brasil, hace más de cincuenta años y se fijaron en el área urbana de la ciudad brasileña fronteriza sur-matogrossense de Curumba, en un lugar que era el antiguo basurero. El artículo contrasta el compromiso internacional asumido por la República Federativa de Brasil en garantizar los derechos humanos de los migrantes e indígenas localizados en el país, con la realidad del pueblo Kamba que, hasta el presente momento, no fue reconocido como indígena por la FUNAI - Fundación Nacional del Indio y, por lo tanto, se encuentra al margen del ejercicio de derechos humanos garantizados a los indígenas y sin disfrutar de derechos y políticas públicas específicas. Revela también la situación de migrante en una sociedad discriminatoria y sin políticas públicas efectivas de acogimiento e igualdad material de derechos humanos entre nacionales y extranjeros, que vive en situación de vulnerabilidad social, víctima de discriminación y de exploración del trabajo. La investigación es de naturaleza exploratoria y son utilizados datos primarios y secundarios recolectados en la doctrina, legislación e investigación en el campo.

\section{Palabras clave}

Derechos Humanos; Frontera; Indígenas y Migración.

\section{Introdução}

Desde o ano de 2013 desenvolvemos projeto de pesquisa interdisciplinar e interinstitucional na região de fronteira entre o Brasil e outros dois países da América do Sul: 
Bolívia e Paraguai, com ênfase nos aspectos de mobilidade (migração) e tráfico de pessoas, em geral para exploração e trabalho ilegal. A partir deste recorte temático, privilegiamos, no âmbito deste estudo, a realidade histórica e atual do povo Kamba, originários da região da chiquitania, terras baixas bolivianas, que há mais de 50 anos está presente em situações precárias nos arredores da cidade de Corumbá/MS/Brasil.

De certa forma, o povo Kamba vive uma situação de marginalização entre as duas culturas, gerando uma invisibilidade construída pelo poder público que nega a eles a identidade de povos indígenas e dos próprios sujeitos que preferem o anonimato. Esta situação de fronteira cultural e reelaboração identitária a partir dos direitos básicos, será analisada, a partir, especialmente das teorias de Fredrik Barth (2000) e Sayad (1998), tendo como referencial o ordenamento jurídico internacional, em especial a Convenção n. 169 da OIT.

Assim, o presente texto traz a relevância dos direitos humanos dos povos indígenas a seus costumes, línguas, religióes e organizaçóes sociais distintas daquelas reconhecidas pelo governo brasileiro (art. 231 da Constituição Federal de 1988), também garantidos em um plano internacional mais abrangente, como a Convenção 169 da OIT e a Declaraçáo Internacional da ONU sobre os Povos Indígenas (2007). Este contexto acaba sendo importante para que os Kamba tenham seus direitos reconhecidos pelo Estado brasileiro, tal qual outras etnias que estiveram em situação semelhante, como o caso dos Kaiowá (Pay Taviterã, como são chamados no Paraguai), no sul de Mato Grosso do Sul.

$\mathrm{Na}$ atualidade muito poucos conhecem a situação histórica dos Kamba. Eles mesmos são receosos de sua visibilidade, por serem estrangeiros sem documentos, o que traz como consequência, por outro lado, o fato de as políticas públicas geralmente não os atingirem. Somente muito recentemente foram realizadas duas pesquisas de doutorado sobre este povo, ressaltando sua história, organização social e particularidades culturais.

Morando junto à cidade, na periferia do município sul-mato-grossense de Corumbá, no bairro Cristo Redentor, reduto São Francisco de Assis, área usada antigamente como "lixão", residem os descendentes dos primeiros Kamba de origem Chiquitano que migraram das tierras bajas na parte oriental da Bolívia, no Departamento de Santa Cruz, em meados do século passado em busca de trabalho e melhoria de condiçóes de vida e, acabaram se tornando vítimas de um duplo preconceito: por serem índios e por serem estrangeiros no Brasil.

Deslocados de seu contexto de origem e inseridos em espaços que não lhes corresponderiam, passaram por dificuldades econômicas, tornaram-se vítimas, aliciadas pelos traficantes, condicionados ao trabalho escravo, tráfico de drogas ou mesmo exploração 
sexual. Por falta de consciência de seus direitos, por vergonha de expor o que passaram e por serem estrangeiros, tornaram-se vulneráveis às condiçóes de ilegalidades com medo de terem que retornar a seu país de origem.

Dessa forma, neste estudo acerca da migração e fronteira, queremos tratar desse povo que encarna em sua trajetória, as duas dimensões, de migração e de fronteira, e em alguns casos, são vítimas de práticas de tráfico e de exploração, sem verem concretizados seus direitos básicos às políticas públicas.

\section{Os Kambas na Bolívia²}

Segundo dados de historiadores e antropólogos, o povo Kamba possui ligaçóes com os Chiquitanos da Bolívia, os quais receberam esta denominaçáo por volta do século XVIII pelos colonizadores europeus. Trata-se de uma denominação genérica dada a diferentes grupos étnicos alocados em uma vasta região chamada de Chiquito (Chiquitania), no atual oriente da Bolívia. A área geográfica do oriente boliviano é compreendida pelo espaço localizado entre o Chaco (sul) e os rios Paraguai (leste) e Rio Grande (oeste).

A Estrada de Ferro Santa Cruz de La Sierra-Corumbá que passava pela Chiquitania, provocou fortes impactos sobre as populaçóes indígenas e não-indígenas da região. No caso dos Kamba, descendentes dos Chiquitano, esse impacto se deu na saída de determinada parcela deste povo das proximidades de Roboré, Tapera e San José de Chiquitos, dando entrada no Brasil em meados do século passado (SILVA, 2011).

Os Kamba e, também, os Camba-chiquitano ${ }^{1}$ são provavelmente o grupo indígena mais numeroso da Bolívia oriental, vivendo nos municípios de Nuflo Chávez, San Ignácio, Velasco e na Província de Pando, todos situados na porção oriental do país (SOUZA, 2009).

Sua vinda ao Brasil se dá em meados do século XX, a partir da construção da ferrovia (Ferrocarril) Santa Cruz de La Sierra, que irá passar pelas cidades de San Jose de Chiquitos e Puerto Suárez. Esse momento foi de grande importância para o processo de migraçáo dos Kamba para o Brasil. E, não podemos esquecer da chegada das missóes jesuíticas nessa região da Chiquitania, no século XIX, que trouxe consigo graves consequências. Dentre estas, tem-se a "mistura" entre diversas comunidades indígenas que viviam ali na região demarcada pelos jesuítas europeus.

2 Alguns itens deste texto fazem parte do texto "A dinâmica e a mobilidade étnico-social dos Kamba e suas ressignificaçóes identitárias" foi publicado originalmente no evento IX Semana de Ciências Sociais da UFMS (2014), com o orientador e dois bolsistas PIBIC da pesquisa (Andréa Lúcia Cavararo Rodrigues e Alyson Matheus de Souza) 


\section{Figura 1. Localização do departamento de Santa Cruz, na atual Bolívia, com destaque para Santa Cruz de la Sierra (seta amarela), San José de Chiquitos (seta vermelha) e Puerto Suárez (seta verde). A Estrada de Ferro Brasil-Bolívia}

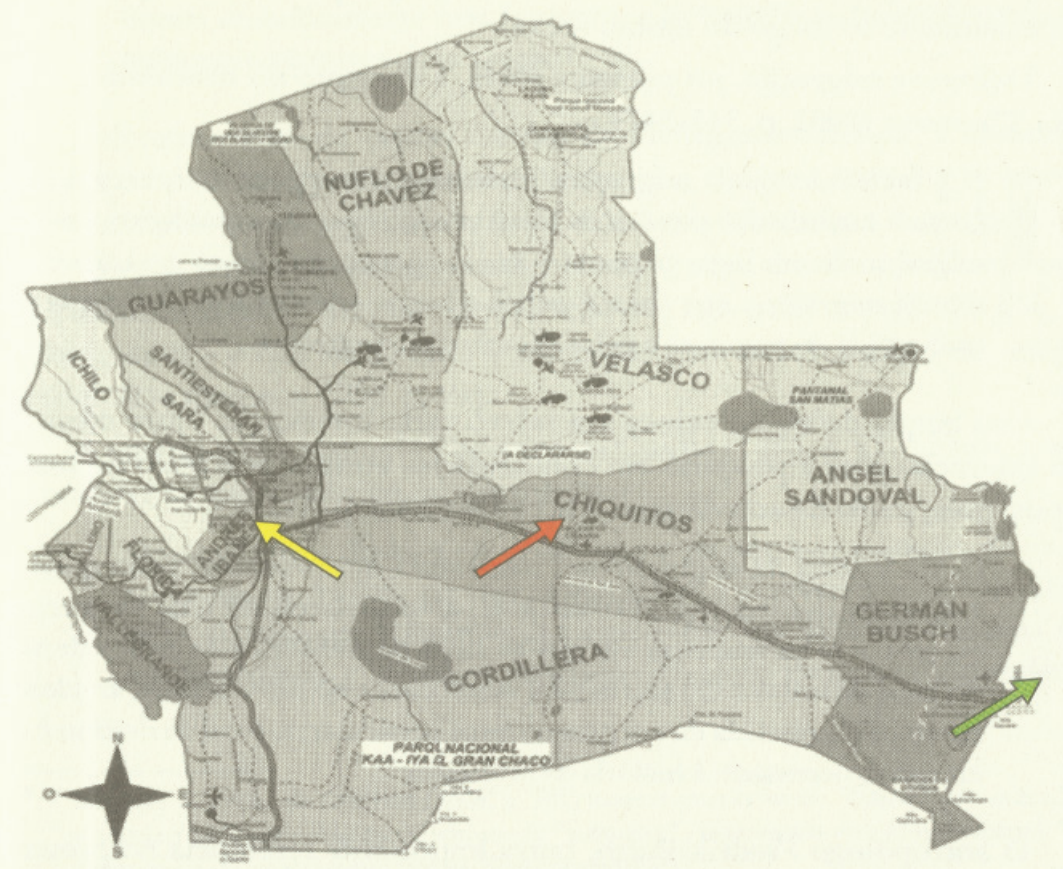

Fonte: SILVA, Giovani José da. Identidades cambiantes: os Kamba na fronteira Brasil-Bolívia. Goiânia, Editoria UFG, 2012, apud SILVA, Ruth Henrique da. 2009.

Através deste mapa podemos ter uma noção da localização dos Kamba na Bolívia antes de sua vinda para o Brasil. A partir dele poderemos analisar o processo migratório deste povo para o Brasil, onde atualmente grande parte encontra-se alocada em uma área urbana, na periferia do município sul mato-grossense de Corumbá, no bairro Cristo Redentor, reduto São Francisco de Assis, área usada antigamente como "lixão" da cidade. Neste local, residem os descendentes dos primeiros Kamba, de origem Chiquitano, que migraram das tierras bajas (terras baixas), na parte oriental da Bolívia, no Departamento de Santa Cruz, em meados do século passado em busca de trabalho e melhoria de condiçôes de vida.

Dessa leva de migrantes indígenas vindos da Bolívia, temos como exemplo o Sr. Nazário. Um jovem senhor, liderança dos Camba-chiquitano (Kamba), que luta pelo 
reconhecimento de seus direitos como indígenas no Brasil. Através de relatos de conversas do Giovani José da Silva (2009) com a liderança, pudemos saber que o Sr. Nazário é uma liderança que luta diariamente em função desse reconhecimento dos Kamba (Camba-chiquitano) através da FUNAI, elucidando em suas falas, apontando para o chão, que "não queremos que nossa história fique no lixo". Isso se dá porque, como já foi dito, eles estão alocados em uma região onde foi o antigo "lixão" de Corumbá-MS.

Por estarem habitando uma localidade que reproduz fortes estigmas com relação aos povos bolivianos e indígenas, acabaram se tornando vítimas de um duplo preconceito: por serem índios e por serem estrangeiros (bolivianos) no Brasil.

\section{Figura 2. Bairro Cristo Redentor, onde reside cerca de 300 indígenas Kamba}

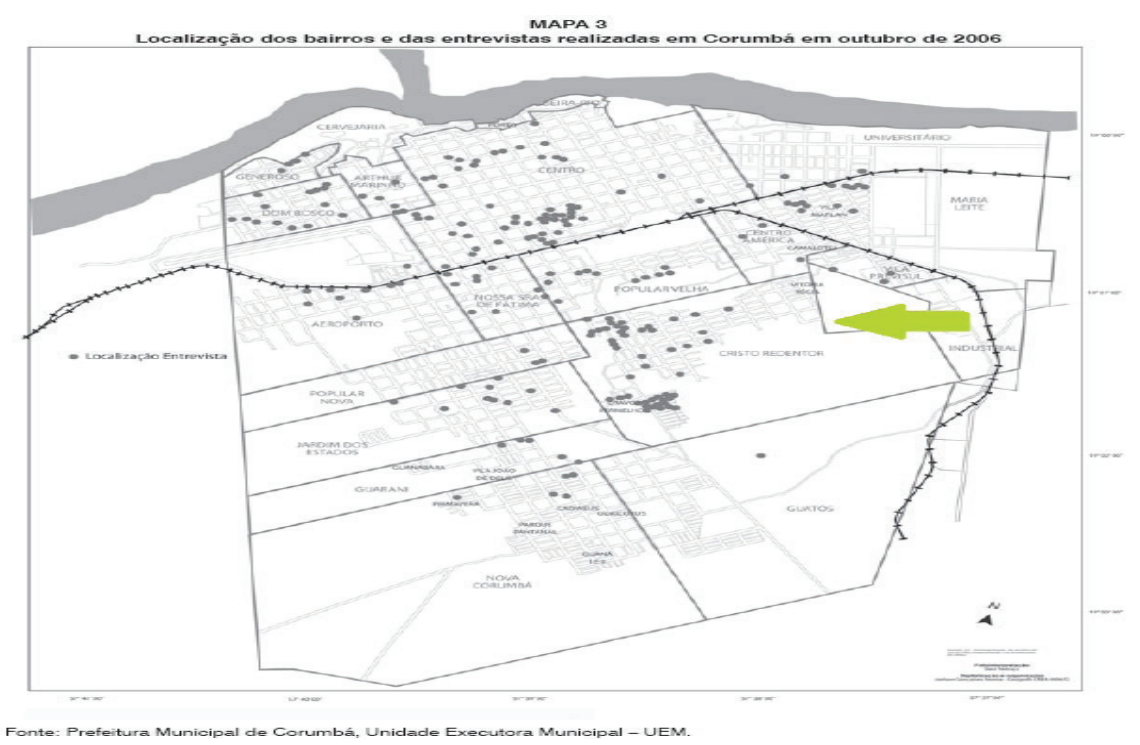

Fonte: http://www.scielo.br/img/revistas/rbepop/v25n2/a05mp03.jpg

E mesmo assim, rodeados por estigmas e exclusóes, eles lutam pelo seu reconhecimento nacional, chegando a se auto afirmarem como brasileiros - isso é algo recorrente entre crianças e adultos -, pois "talvez estejam com medo de náo receberem os mesmos direitos que os brasileiros têm" (informação oral) ${ }^{3}$.

Deslocados de seu contexto de origem e inseridos em espaços que não lhes corresponderiam e por passarem por dificuldades econômicas tornaram-se vítimas de trabalhos

3 Dados coletados em pesquisa de campo realizada na região de Corumbá. 
subalternos e informais. E é assim que encontramos os Kamba, "desterritorializados, migrantes e sofrendo dupla discriminação, por serem índios e, ao mesmo tempo, por serem considerados estrangeiros no Brasil: eis a situação atual dos Kamba” (SILVA, 2012).

Por uma deficiência dos órgáos responsáveis pelas políticas para migrantes e indígenas em não estabelecerem diálogo com este povo; vergonha de si mesmo, e/ou; por constrangimento para expor o que passaram e por serem estrangeiros, tornaram-se vulneráveis às condiçóes de ilegalidade por medo de terem que retornar a seu país de origem.

\section{Os Kamba em Corumbá/Brasil}

Corumbá é um município da Região Centro-Oeste do Brasil, situado no estado de Mato Grosso do Sul, à margem esquerda do rio Paraguai e também na fronteira entre o Brasil, o Paraguai e a Bolívia (situação conhecida como tríplice fronteira). Considerado historicamente o primeiro polo de desenvolvimento da região, abriga $60 \%$ do território pantaneiro, e é o $11^{\circ}$ maior município em extensão territorial do Brasil (e o maior fora da região Norte), com aproximadamente $65 \mathrm{mil} \mathrm{km}^{2}$. De acordo com estimativas do IBGE de 2012, possui uma população de aproximadamente 105 mil habitantes, sendo a terceira cidade mais populosa de Mato Grosso do Sul, além de ser o $5^{\circ}$ município fronteiriço mais populoso do Brasil.

Corumbá está conurbada com mais três cidades: Ladário, única cidade vizinha brasileira, além das cidades Bolivianas de Puerto Suarez e Puerto Quijarro. Com isso existe uma rede urbana de cerca de 150.000 pessoas. A proximidade com a Bolívia, $15 \mathrm{~km}$ até a fronteira seca com esse país, e a distância das demais cidades do Brasil, traz grandes diferenciais culturais para essa cidade fronteiriça.

Tanto os Kamba, quanto uma pequena parcela destes que se autodenomina Camba-chiquitano - iremos discutir sobre este termo mais à frente -, residem na periferia da cidade de Corumbá, no Reduto de São Francisco, e estão alocados nesta região desde a sua chegada em Corumbá, em meados dos séculos XX. Entre os diversos fatores que influenciaram na vinda dos Kamba para a cidade de Corumbá, consideramos de suma importância a Ferrovia Santa Cruz de La Sierra (BOL) - Corumbá (BRA) (1939-1954); e as consequências da implantação das missôes jesuíticas europeias fundadas pelos padres da Companhia de Jesus.

Levando em consideração as narrativas coletadas por Giovani José da Silva os Kamba entrevistados temiam a desaparição do seu povo:

[...] Alguém que soubesse ouvir, escrever e depois divulgar a história dos Kamba, que, na opinião dele, irão desaparecer em breve... Isso porque, de acordo com o velho narrador, as geraçóes mais novas sequer se sabem 
indígenas, já nasceram em ambiente urbanizado, completamente sem perspectivas de fazerem Camba-Chiquitano num meio hostil a "índios" e "estrangeiros" (SILVA, 2009, p. 37-38).

Desde que chegaram ao Brasil, os Kamba são vistos pelos não-índios como estrangeiros, seja pela população corumbaense ou mesmo pelo Estado brasileiro. Dificultando o reconhecimento da identidade indígena desse povo no estado de Mato Grosso do Sul pela FUNAI (Fundação Nacional do Índio).

Com relação à atuação da FUNAI sobre o reconhecimento dos Chiquitano em território brasileiro, Alda Lúcia M. de Souza nos diz que:

No Brasil, os Chiquitanos sempre foram reconhecidos pela população regional como "índios bolivianos". Apenas recentemente, há cerca de 10 anos, o órgão indigenista oficial (FUNAI) reconheceu a existência dos Chiquitanos em territórios brasileiro (SOUZA, 2009, p.11).

E é esta a situação em que se encontram os Kamba no território brasileiro: um grupo reconhecido como "índios bolivianos", por terem migrado da Bolívia para o Brasil no século XX, sem reconhecimento oficial pela FUNAI como indígenas no Brasil, impedidos de usufruir de políticas públicas destinadas às comunidades indígenas brasileiras.

A partir desses pressupostos já apresentados, iremos apresentar a partir de agora um breve panorama sobre os Kamba e o ordenamento jurídico internacional de direitos humanos.

\section{A Proteção Internacional dos Direitos Humanos das Minorias: Índios e Migrantes}

A situação jurídica dos Kamba no Brasil demonstra as dificuldades encontradas pelos países em efetivar, em seus territórios, o compromisso assumido em âmbito internacional de garantir os direitos humanos, quando se torna país destinatário de migrantes, fazendo com que a igualdade material não seja realizada e que os estrangeiros sofram todas as formas de violaçóes de direitos durante o processo de deslocamento e de permanência no país receptor.

O gozo de direitos fundamentais por estrangeiros enfrenta barreiras no Brasil de várias naturezas, seja pela: ausência, incompletude ou irregularidade dos documentos pessoais necessários para acesso a direitos por parte dos estrangeiros; dificuldade de comunicação com a sociedade local em virtude de diferenças das línguas ou discriminação que estrangeiros em situação vulnerabilidade social sofrem da sociedade que os recebe.

Segundo Antônio Cançado Trindade (2013, p.7) em tempos da chamada "globalização", "as fronteiras se abriram para o capital, bens e serviços, mas, infelizmente, se 
fecharam para os seres humanos". O processo de "globalização" que presume a ampla participação de todos, na verdade "esconde a fragmentação do mundo contemporâneo, e a exclusão e marginalização social de segmentos cada vez maiores da população". Nesse mundo contemporâneo, convive lado a lado, o progresso material de uns e a exploração de muitos, principalmente de "imigrantes em situação irregular, prostituição forçada, tráfico infantil, trabalho forçado e escravo, em meio ao aumento da pobreza e da exclusão e marginalização social”.

A República Federativa do Brasil é signatária de tratados internacionais que reconhecem que há um núcleo de direitos humanos universais da pessoa humana e que independe da origem, raça ou etnia. $\mathrm{O}$ compromisso internacional assumido visa evitar a reprodução de violaçóes de direitos humanos em função da dicotomia entre o interno e o externo. Segundo Flávia Piovesan (2013, p. 139) “ao longo da história, as mais graves violaçóes aos direitos humanos tiveram como fundamento a dicotomia do eu versus o outro, em que a diversidade era captada como elemento para aniquilar direitos".

A desconfiança e o medo daquilo que é diferente sempre foram combustíveis para atos de discriminação e segregação. No fenômeno migratório, essa máxima é igualmente válida. As maiores atrocidades cometidas contra a pessoa humana e violaçóes a direitos fundamentais foram motivadas pela ideia de superioridade e de intolerância.

$\mathrm{O}$ arranjo internacional, portanto, criou um sistema global de proteção de direitos humanos que tem como fim precípuo impedir a ocorrência de novas violaçóes de direitos básicos do ser humano. Esse sistema tem como uma de suas premissas a igualdade formal entre os povos do globo, o que possibilita a garantia de direitos a todas as pessoas, sem qualquer tipo de distinção, independentemente de qualquer condição social, econômica ou política.

Antes de se pensar o ser humano como cidadão universal, entendia-se que o Estado somente tinha obrigação de salvaguardar direitos dos seus nacionais, sendo muito pouco, ou quase nada, os direitos que eram tutelados nas legislaçôes domésticas aos estrangeiros. Entretanto, a nova concepção sobre o papel do Estado na tutela dos direitos universais do ser humano, surge para fazer um contraponto à antiga dicotomia existente entre Estado e cidadão, o qual governava todas as açóes do Estado na proteção de direitos inerentes à pessoa. Assim, com a sistematização de um mecanismo de proteção dos direitos da pessoa humana, são introduzidos novos sujeitos no direito internacional e o papel dos Estados nacionais na tutela e respeito de garantias humanas é repensado, tornando-se a questão da proteção e do exercício de direitos fundamentais mais complexas.

A titularidade universal de certos direitos convencionados entre Estados signatários de tratados internacionais fez com que a pessoa humana tivesse um núcleo de direitos independentemente da nacionalidade ou do local de residência do seu titular, eliminando 
as diferenças entre os nacionais e estrangeiros no tocante a viver em condiçóes dignas, fazendo com que existisse a preocupação de proteção global e local dos sujeitos de direitos, bem como da possibilidade de se responsabilizar o Estado nacional de forma externa pelo descumprimento ou violações às garantias universais, pelos instrumentos de fiscalização e responsabilização internacionais.

A universalidade de direitos influi diretamente na questão migratória e nos direitos dos migrantes, uma vez que, o Estado nacional assume a obrigação internacional de garantia e proteção dos direitos fundamentais universais de todos aqueles que estejam em seu território, não importando, a origem, a situação jurídica, a cor, a raça ou a nacionalidade dos titulares desses direitos. Com a universalidade, o Estado assume a obrigaçáo de proteger a dignidade da pessoa humana, o que implica em um dever de tutela dos direitos humanos através de proibiçôes às condutas violadoras de direitos praticadas principalmente por particulares (DIMOULIS; MARTINS, 2011).

Há que se destacar que a universalidade ainda não é absoluta, pois há uma relativização dos direitos em função de critérios culturais e estágio de desenvolvimento do país. Tal visão é resultado do consenso de duas correntes: a universalista e a relativista (culturalista). A primeira reconhece o direito fundamental como universal e a segunda entende que os direitos civis e políticos são "expressóes de ideologias e da cultura ocidental" e que, portanto, "deviam ser relativizados conforme o estágio de desenvolvimento e a tradição cultural de cada povo" (SILVEIRA, 2010, p. 239).

$\mathrm{O}$ artigo $5^{\circ}$ da Declaração de Viena representa bem o consenso das duas correntes, na primeira parte apresenta a universalidade ao dizer: "todos os direitos do homem são universais, indivisíveis, interdependentes e inter-relacionados. A comunidade internacional tem de considerar globalmente os Direitos do homem, de forma justa e equitativa e com igual ênfase". E a relativização, na segunda parte: "embora se devam ter sempre presente o significado das especificidades nacionais e regionais e os antecedentes históricos, culturais e religiosos, compete aos Estados, independentemente dos seus sistemas político, econômico e cultural, promover e proteger todos os Direitos do homem e liberdades fundamentais".

A universalização sempre buscou a padronização dos direitos entre os povos, o que ocorreu quando se reconheceu internacionalmente como direito humano fundamental a "dignidade da pessoa humana". Todavia a completude da interpretação do conceito de dignidade da pessoa humana é relativa, uma vez que é construída democraticamente por cada sociedade em conformidade com seus próprios valores culturais. Para Ingo Wolfgang Sarlet (2001, p. 134) a adoção da dignidade da pessoa humana como bem jurídico absoluto, encontra-se em aberto, pois sua construçáo dependerá da vontade do intérprete em conformidade com um sentido cultural e socialmente vinculado. 


\subsection{Os Direitos Humanos das Minorias}

Reconhecer que os direitos humanos devem ser vislumbrados como multiculturais implica na aceitação de que a discordância é essencial em uma sociedade democrática e que é "fator preponderante para os avanços do conhecimento, sendo os abalos das opiniôes tradicionais necessários para a produção de respostas ou concepçôes novas ou mais abrangentes" (CARDOSO, 2010, p. 21).

A dignidade da pessoa humana em um Estado democrático pluralista tem por fundamento a liberdade de pensamento de cada pessoa humana e a possibilidade de manifestar seu pensamento e de lutar por viver segundo as suas próprias opinióes. O respeito ao pensamento de cada um convive com o respeito ao pensamento do outro, em equivalência de proteção. Nessa ótica, a autonomia e a liberdade individual não podem ser suprimidas pela vontade da maioria (NOVAIS, 2007).

O pluralismo propicia o respeito à diversidade e à preservação de culturas que não representam a maioria. A Declaraçáo Universal da Diversidade Cultural da UNESCO declara que a diversidade cultural é patrimônio comum da humanidade e deve ser reconhecida e consolidada em benefício das gerações presentes e futuras:

Artigo 1 - A diversidade cultural, patrimônio comum da humanidade A cultura adquire formas diversas através do tempo e do espaço. Essa diversidade se manifesta na originalidade e na pluralidade de identidades que caracterizam os grupos e as sociedades que compóem a humanidade. Fonte de intercâmbios, de inovação e de criatividade, a diversidade cultural é, para o gênero humano, tão necessária como a diversidade biológica para a natureza. Nesse sentido, constitui o patrimônio comum da humanidade e deve ser reconhecida e consolidada em benefício das geraçóes presentes e futuras.

A Declaração também prevê o pluralismo cultural como a resposta para a convivência das diversas identidades culturais:

Artigo 2 - Da diversidade cultural ao pluralismo cultural

Em nossas sociedades cada vez mais diversificadas, torna-se indispensável garantir uma interação harmoniosa entre pessoas e grupos com identidades culturais a um só tempo plurais, variadas e dinâmicas, assim como sua vontade de conviver. As políticas que favoreçam a inclusão e a participação de todos os cidadãos garantem a coesão social, a vitalidade da sociedade civil e a paz. Definido desta maneira, o pluralismo cultural constitui a resposta política à realidade da diversidade cultural. Inseparável de um contexto democrático, o pluralismo cultural é propício aos intercâmbios culturais e ao desenvolvimento das capacidades criadoras que alimentam a vida pública. 
O pluralismo e a diversidade cultural na medida em que defendem a convivência e o respeito entre os diferentes retoma a discussão sobre qual o mínimo fundamental de direito que a pessoa humana possui e que se encontra entre as acepçóes majoritárias e minoritárias e quais são os direitos que são culturais.

Flávia Piovesan afirma que o diálogo entre as culturas com respeito à diversidade e ao reconhecimento do outro, como ser pleno de dignidade e de direitos é condição para a celebração de uma cultura dos direitos humanos, inspirada pela observância do "mínimo ético irredutível" alcançado por um universalismo de confluência e não de imposição (2008, p. 25). No mesmo sentido Antônio Augusto Cançado Trindade afirma que a universalidade é enriquecida pela diversidade cultural, a qual jamais pode ser invocada para justificar a denegação ou violação dos direitos humanos (1991, p. 54).

O mínimo existencial da pessoa humana congrega os direitos humanos de todos, justamente por serem humanos, independentemente da ideia de pertencimento a grupos majoritários ou minoritários e reside no reconhecimento do outro como ser pleno de dignidade e de direitos. Segundo Flávia Piovesan "o valor da dignidade da pessoa humana impóe-se como núcleo básico e informador de todo o ordenamento jurídico, como critério e parâmetro de valoração a orientar a interpretação e compreensão do sistema constitucional" (2003, p. 13).

Todavia, a evolução dos direitos humanos com o reconhecimento da diversidade cultural e da dignidade humana nos documentos internacionais não são suficientes para proporcionar a efetividade dos direitos às minorias. Segundo Antônio Augusto Cançado Trindade (2003, p. 313):

[...] o recrudescimento das diferenças, em um mundo cada vez mais transparente, parece haver realçado em nossos dias a importância da questão da proteção das minorias (culturais, étnicas, linguísticas, religiosas, dentre outras) e, sua condição como resultado de distintas formas, inaceitáveis, de dominação e exclusão (cultural, política, econômica, social e até mesmo legal). É inegável que o fato de pertencer a uma minoria - e.g., étnica ou religiosa - às vezes, e não raro, se torna uma fonte de insegurança pessoal, - como ilustra o crescimento e agravamento da xenofobia em diferentes partes do mundo.

Surge, portanto, nesse complexo cenário, uma nova discussão sobre a real efetividade na proteção aos direitos fundamentais garantidos à determinados grupos de pessoas, chamados de "minorias". Segundo Ingo Wolfgang Sarlet (2012) na primeira fase de reconhecimento, o princípio da igualdade corresponderia a noção de que todos seriam iguais independentemente do conteúdo do tratamento dispensado e das condiçóes e circunstâncias pessoais, razão pela qual, nesta perspectiva, o princípio da igualdade de certo modo correspondia à exigência da generalidade e prevalência da lei, típica do estudo constitucional de matriz liberal. 
Os tratados internacionais ao declarar direitos com fundamento na igualdade, o fazem formalmente, uma vez que, para o direito, as pessoas são iguais sendo irrelevante a origem, etnia, cor da pele, sexo, condição social. Todavia, o que se vê é que muitas pessoas não usufruem da igualdade porque estáo em condiçóes de vulnerabilidade social que as impedem de exercer a sua autonomia e se tornam vítimas de tratamentos degradantes e desumanos.

A constatação do descompasso entre a igualdade declarada nos documentos internacionais e a vivenciada diuturnamente pelas pessoas, fez com que fosse atribuído o sentido material à dignidade humana. Conforme Ingo Wolfgang Sarlet (2012):

a atribuição de um sentido material à dignidade, que não deixou de ser também uma igualdade de todos perante a lei, foi uma reação à percepçáo de que a igualdade formal não afastava, por si só, situaçóes de injustiças, além de se afirmar a exigência de que o próprio conteúdo da lei deveria ser igualitário, de modo que de uma igualdade perante a lei e não da aplicação da lei, se migrou para uma igualdade também na lei. Igualdade em sentido material, além, disso, significa a proibição de tratamentos arbitrários, ou seja, a vedaçáo de utilização, para efeito de estabelecer as relaçóes de igualdade e desigualdade, de critérios intrinsecamente injustos e violadores da dignidade da pessoa humana, de tal sorte que a igualdade, já agora na segunda fase de sua compreensão na seara jurídicoconstitucional, opera como exigência de critérios razoáveis e justos para determinados tratamentos desiguais.

A atribuição do sentido material à igualdade tem como pressuposto a visão do sujeito titular de direitos com suas peculiaridades e particularidades. Para Gilmar Ferreira Mendes "pensar a igualdade segundo o valor da fraternidade significa ter em mente as diferenças e as particularidades humanas em todos os aspectos". E continua "a tolerância, segundo o princípio da igualdade, exige a consideração do outro respeitando as suas peculiaridade e idiossincrasias. A igualdade só pode ser igualdade numa sociedade pluralista quando há reconhecimento do direito à diferença e, em consequência, aceitação das minorias" (MENDES, s/d, p. 5).

A compreensão do direito à diferença demanda a delimitação dos grupos sociais que se encontram em situação de vulnerabilidade, para se identificar, com precisão, quais são os direitos que a estes devem ser garantidos, uma vez que, tratar o ser humano com igualdade, mas de modo genérico, tornou-se ineficiente. Para que ocorra a efetiva proteção de direitos, há a necessidade de um olhar específico para cada sujeito de direitos fundamentais, em suas peculiaridades, a fim de ser delimitado quais são as suas maiores necessidades, e supri-las, a fim de se construir uma sociedade mais justa.

Os Kamba são índios migrantes que se encontram há mais de cinquenta anos em território brasileiro e que até agora não receberam a atenção necessária do governo, não 
existindo uma política pública que os atenda enquanto migrantes ou indígenas, fazendo com que vivam em situação de vulnerabilidade social em uma área onde funcionava o lixão da cidade, sem o mínimo de infraestrutura, marginalizados em uma sociedade discriminatória.

\subsection{Os Direitos Humanos dos Indígenas}

A República Federativa do Brasil é signatária da Convenção 169 da OIT que ingressou no nosso ordenamento jurídico pelo Decreto Legislativo n. 143, de 20 de junho de 2002 e que estabelece no artigo $3^{\circ}$ que "os povos indígenas e tribais deveráo gozar plenamente dos direitos humanos e liberdades fundamentais, sem obstáculos nem discriminação".

A convenção fixa como sujeitos de direitos: i. os povos tribais em países independentes, cujas condiçóes sociais, culturais e econômicas os distingam de outros setores da coletividade nacional, e que estejam regidos, total ou parcialmente, por seus próprios costumes ou tradiçóes ou por legislação especial e ii. aos povos em países independentes, considerados indígenas pelo fato de descenderem de populaçóes que habitavam o país ou uma regiâo geográfica pertencente ao país na época da conquista ou da colonização ou do estabelecimento das atuais fronteiras estatais e que, seja qual for sua situação jurídica, conservam todas as suas próprias instituições sociais, econômicas, culturais e políticas, ou parte delas (artigo $1^{\circ}$ ).

Estudos antropológicos afirmam que os Kamba são índios bolivianos, enquadrandose no art. $1^{\circ} \mathrm{da}$ Convenção, todavia não se encontram em seu país de origem e sim em território estrangeiro, na fronteira entre Brasil/Bolívia, vivendo em núcleo urbano e já possuem descendentes brasileiros, o que dificulta o exercício de direitos como indígenas.

Pelo compromisso internacional, o governo brasileiro assumiu a responsabilidade de desenvolver, com a participação dos povos interessados, uma ação coordenada e sistemática com vistas a proteger os direitos dos indígenas e a garantir o respeito pela sua integridade $\left(\right.$ art. $\left.2^{\circ}\right)$. Essa ação inclui medidas:

a) que assegurem aos membros desses povos o gozo, em condiçóes de igualdade, dos direitos e oportunidades que a legislação nacional outorga aos demais membros da população;

b) que promovam a plena efetividade dos direitos sociais, econômicos e culturais desses povos, respeitando a sua identidade social e cultural, os seus costumes e tradiçốes, e as suas instituiçôes;

c) que ajudem os membros dos povos interessados a eliminar as diferenças socioeconômicas que possam existir entre os membros indígenas e os demais membros da comunidade nacional, de maneira compatível com suas aspiraçóes e formas de vida. 
As normas citadas estabelecem formas de proteção relacionadas à diversidade e igualdade material e, ao mesmo tempo em que reconhece as diferenças culturais dos indígenas, estende-lhes os direitos sociais previstos na legislação pátria para os nacionais.

A Convenção protege os valores e práticas sociais, culturais, religiosas e espirituais próprios dos indígenas e fixa como diretriz a adoção de políticas públicas que levem em consideração os problemas que lhes sejam apresentados, tanto coletiva como individualmente, bem como a participação e cooperação dos indígenas, na adoção de medidas voltadas a aliviar as dificuldades experimentadas ao enfrentarem novas condiçóes de vida e de trabalho (art. 5\%).

Pela Convenção, o requisito para o reconhecimento dos indígenas é a auto identificação, por este critério, a pessoa precisa se reconhecer como indígena para se tornar sujeito de direitos, ainda que o auto reconhecimento seja verificado por alguém que recebeu a competência de analisar a qualidade de indígena ou náo, que no Brasil é realizada por antropólogos a serviço da FUNAI - Fundação Nacional do Índio. Nesse ponto, tem-se que nos estudos encomendados pela FUNAI, os Kamba foram reconhecidos como indígenas, todavia nos estudos de campo desenvolvidos, muitos não se reconhecem como indígenas e como já existem muitos descendentes nascidos no Brasil, há preferência de alguns em serem brasileiros não indígenas.

A ausência de unanimidade da consciência da identidade indígena entre os Kamba e a demora no reconhecimento oficial da FUNAI, faz com que eles náo sejam incluídos em uma política pública específica, o que compromete direitos garantidos nos tratados internacionais como da autodeterminação e autogoverno, fazendo com que permaneçam na invisibilidade, enquanto indígenas.

A Declaração das Nações Unidas sobre os Direitos dos Povos Indígenas afirma o direito à autodeterminação, devolvendo aos indígenas o direito de buscar livremente seu desenvolvimento econômico, social e cultural, bem como de autogoverno em relação aos assuntos internos e locais bem como de disporem de meios para financiar suas funçóes autônomas. Tal determinação retira a visão equivocada de incapacidade ou capacidade parcial do indígena dependente de um órgão curador que realize a sua proteção e que realize a mediação das suas relaçóes com os nacionais (artigos $3^{\circ}$ e $4^{\circ}$ ).

Pelo artigo $5^{\circ}$, os povos indígenas têm direito de conservar as suas próprias instituições políticas, jurídicas, econômicas, sociais e culturais, ao mesmo tempo em que têm direito de participar plenamente, caso o desejem, da vida política, econômica, social e cultural do Estado.

O fato dos Kamba estarem em uma área urbana desde que cruzaram a fronteira também dificulta o seu reconhecimento como indígenas, pois o "modelo" jurídico de indígena no Brasil é do índio que vive aldeado em terras tradicionalmente ocupadas pelos seus ascendentes. 


\section{Conclusões}

A fronteira é, de fato, vivida por seus habitantes como um espaço contínuo de tráfego de pessoas, mercadorias, conhecimentos e tradições, ou seja, são coletividades que se vinculam através da linha divisória entre os países e que muitas vezes desconhecem os conceitos jurídicos de territorialidade.

Os Kamba são considerados "índios bolivianos" embora nas entrevistas realizadas se encontrem duas dicotomias: índio/não índio e brasileiro/boliviano. É comum a geração que nasceu em solo brasileiro e que descende dos migrantes se autodeclarar brasileiros e tentar a integração e náo o reconhecimento das diferenças, situaçáo que dificulta o reconhecimento da etnia, vez que a normativa internacional vigente é pela auto identificaçáo e do reconhecimento de uma consciência da identidade indígena.

Os Kamba também não se encaixam no modelo jurídico tradicional brasileiro representado pelo índio aldeado que vive em terras tradicionalmente ocupadas pelos seus ascendentes, considerados povos pré-colombianos, pois são migrantes que cruzaram a fronteira e se estabeleceram em uma área urbana e passaram a viver como migrantes e não como índios.

Para serem destinatários de políticas públicas de direitos humanos e exercerem plenamente os direitos de autodeterminação e autogoverno, os Kamba precisam ser reconhecidos pela Fundação Nacional do Índio - FUNAI como indígenas, situação que não ocorreu até o presente momento, embora tenha existido um estudo antropológico no passado em que o parecer foi pelo reconhecimento como indígenas.

Da mesma forma, os Kamba também não são destinatários de políticas públicas específicas para migrantes, estando desde a vinda para o país em condição de vulnerabilidade social, ocupando uma área onde funcionava o lixão da cidade, sendo vítimas de discriminação e exploração pela sociedade local.

A omissáo do Estado brasileiro em reconhecer os Kamba como indígenas e, portanto, sujeitos de direitos com políticas públicas específicas, compromete a manutenção da identidade indígena e o exercício de direitos humanos básicos pertencentes ao sistema global de direitos humanos.

A falta de uma política pública nacional para os migrantes, também sujeita os estrangeiros a condições de vulnerabilidade social, pois não há uma política de acolhimento e garantia mínima de direitos.

O estrangeiro em situação de vulnerabilidade social disputa da insuficiente infraestrutura de serviços com os nacionais, ao mesmo tempo em que são vítimas de violaçóes de direitos humanos, tais como exploração sexual e trabalho em condiçôes análogas a de escravo. 
Embora a República Federativa do Brasil seja signatária de tratados internacionais sobre direitos humanos que reconhecem os direitos da pessoa humana independente de origem e etnia, bem como das minorias e suas diversidades culturais, o que verificamos em relação aos Kamba é a sua invisibilidade social como consequência da negativa dos direitos humanos básicos e que exige com urgência a inclusáo dessa etnia em uma política pública de minoria.

\section{Referências}

ALBUQUERQUE, José Lindomar C. Fronteiras em movimento e identidades nacionais: a imigração brasileira no Paraguai. Fortaleza, UFC, 2005. Tese (Doutorado em Sociologia)

AMARAL, Ana Paula M., CARVALHO, Luciani C. Direito do Estrangeiro ao Sistema Único de Saúde: Um olhar para as fronteiras de Mato Grosso do Sul. Campo Grande: Ed. UFMS, 2013.

BARTH, Fredrik. O guru, o iniciador e outras variaçóes antropológicas. Tradução de John Cunha Comerford. Rio de Janeiro: Contra Capa Livraria, 2000.

CARDOSO, Alenilton da Silva. A proteção das minorias na fixação do mínimo ético sobre direitos humanos In SILVEIRA, Vladmir Oliveira da. Estudos e debates em direitos humanos. Florianópolis: Conceito Editorial, 2010.

CARDOSO DE OLIVEIRA, Roberto \& BAINES, Stephen (Org.). Nacionalidade Etnicidade em Fronteiras. Brasília, Editora UNB. 2005.

CASTLES, Stephen. Globalização, Transnacionalismo e novos fluxos migratórios dos trabalhadores convidados a migraçóes globais. Lisboa: fim de século, 2005.

COSTA, Edgar Aparecido. COSTA, Gustavo Vilela Lima, OLIVEIRA, Marco Aurélio Machado. (org.) Estudos Fronteiriços. Campo Grande: Ed. UFMS, 2010.

COSTA, Edgar Aparecido. SILVA, Giane Aparecida Moura, OLIVEIRA, Marco Aurélio Machado. (org). Despertar para a fronteira. Campo Grande: Ed. UFMS 2009.

COSTA, Gustavo, Vilela Lima. OLIVEIRA, Marco Aurélio Machado, SIQUEIRA, Kiase Moraes. (org). Fronteiras: Conflitos, Integraçáo e Políticas Públicas. Campo Grande: Ed. UFMS, 2011.

DELGADO, Paulo Sérgio, SILVA, Ruth Henrique. Constructos identitários e territorialidade: ser ou não ser Camba no Brasil. In: Revista Ibero-americana XI, 42; 2011. Pg. 127-141;

DIMOULIS, Dimitri. MARTINS, Leonardo. Teoria Geral dos Direitos Fundamentais. 3o ed. São Paulo: Revista dos Tribunais, 2011. 
FARIAS, Adriano Lúcio Bezerra. Migração e presença Camba-Chiquitano em Mato Grosso do Sul: fronteira, práticas culturais e construçóes identitárias. Trabalho científico apresentado no VI Congresso Internacional de História. ISSN 21764446, 2013.

MENDES, Gilmar Ferreira. A jurisdiçáo constitucional no Brasil e seu significado para a liberdade e igualdade. Disponível em: <http://www.stf.jus.br/arquivo/cms/ noticiaartigodiscurso/anexo/munster_port.pdf>. Acesso: 13 mai. 2015.

NOVAIS, Jorge Reis. Direitos como trunfos contra a maioria. IN CLÉVE, Clemérson Merlin; SARLET, Ingo Wolfgang; PAGLIARINI, Alexandre Coutinho (Coords.). Direitos humanos e democracia. Rio de Janeiro: Forense, 2007.

PIOVESAN, Flávia. Direitos humanos e o Direito Constitucional Internacional. 9a ed. São Paulo: Saraiva, 2008.

. Direitos Humanos e o Trabalho. Revista da AMATRA II, São Paulo, 2003.

. Migrantes sob a perspectiva dos direitos humanos. Revista Diversitas. Março/ setembro. São Paulo: USP, 2013.

SARLET, Ingo Wolfgang. Dignidade da pessoa humana e direitos fundamentais na Constituiçáo Federal de 1988. Porto Alegre: Livraria dos Advogados, 2001.

SARLET, Ingo Wolfgang. MARINONI, Luiz Guilherme. MITIDIERO, Daniel. Curso de Direito Constitucional. São Paulo: Editora Revista dos Tribunais, 2012.

SAYAD, Abdelmalek. A Imigraçáo ou os Paradoxos da Alteridade, prefácio de Pierre Bourdieu; tradução Cristina Muracho. São Paulo: Ed. da Universidade de São Paulo, 1998.

SILVEIRA, Vladmir Oliveira da. Direitos humanos: conceitos, significados e funçóes. São Paulo Saraiva, 2010.

TRINDADE, Antônio Augusto Cançado. A proteçáo internacional dos Direitos Humanos no limiar do novo século e as perspectivas brasileiras. São Paulo: Saraiva, 1991.

. Tratado de direito internacional dos Direitos humanos. V. 3. 2. ed. rev. atual. Porto Alegre: S. A. Fabris, 2003.

. Voto Concurrente del Juez A.A. Cançado Trindade. Condición jurídica y derechos de los migrantes indocumentados. Opiniáo consultiva OC-18/03. Disponível em: <www.corteidh.or.cr/docs/opiniones/seriea_18_esp.pdf>. Acesso: 14 mai 2015. 